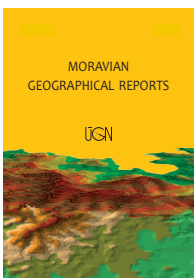

MORAVIAN GEOGRAPHICAL REPORTS

\title{
Visibility and perception analysis of city monuments: The case of Bratislava city centre (Slovakia)
}

\author{
Ján OŤAHEL' a,b *, Vladimír IRA ${ }^{\text {a }}$, Zuzana HLAVATÁ c ${ }^{\text {, }}$ Róbert PAZÚR ${ }^{\text {a,d }}$
}

\begin{abstract}
City monuments attract tourists, especially at places with efficient viewpoints. The conditions of visibility of eight historical monuments in the city of Bratislava were evaluated using GIS on a $3 D$ landscape, employing the criteria of distance, impressiveness, size and the number of visible monuments. The visual quality of 15 selected viewpoints was verified by surveying more than 300 respondents about their views of the monuments from similar locations. These approaches allow us to assess the conformity of visual quality analysis conducted in objective and subjective ways. The most attractive viewpoints ranked by observers were remote from the historic town and provided views of several monuments, as well as a comprehensive panoramic view of the centre of Bratislava. The approaches to assessing visual quality analysis presented in this study represent a comprehensive way of defining and verifying which places are the best for effective sightseeing of a city's monuments.
\end{abstract}

Keywords: visibility analysis; visitor perceptions; viewpoints attractiveness assessments; sightseeing guidance; Bratislava monuments, Slovakia

Article history: Received 10 May 2017; Accepted 10 March 2018; Published 31 March 2018

\section{Introduction}

The image of a city held by a broad range of visitors such as tourists and business persons, is a phenomenon of interest to those visiting any given city. Monuments are important for a city's image, as they attract tourists (Zemła, 2016). Thus, the efficient organisation of movement and orientation in a city is a primary concern of decision makers such as city planners and architects, as well as tourists and tourist guides. The rapid growth of urban tourism has led to an increasing demand to develop measures that cope better with a large number of visitors (Bauder and Freytag, 2015). Convenient sightseeing in cities can be oriented to selected monuments and landmarks or to objects related to urban tourism (Ashworth and Page, 2011; Edwards et al., 2008; Garnero and Fabrizio, 2015). Thus, the planning of sightseeing in a city raises the question of how to find a convenient sightseeing route and the best places for seeing the monuments ( $\mathrm{Di}$ Lorenzo et al., 2012).
Perceptions of an urban environment are multidimensional, as they depend on the individualities of observers, inhabitants and tourists - subjects, in the most general sense. Compiling mental maps of differentiated visual quality by defining how a city's inhabitants perceive the city's main visual elements is one of the most influential approaches in the analysis of city perceptions (Lynch, 1960). Regarding selected American cities, Lynch (1960) showed that although individual differences in perception are psychologically interesting, there is a prevailing general image common to the majority of a city's inhabitants. The inhabitants' shared evaluation of - or collective agreement about - the city's visual quality was determined by "the interaction of a single physical reality, a common culture, and a basic physiological nature" (Lynch, 1960, p. 7). Lynch (1960) suggested accepting some preconditions for agreement in search of the visual quality of the city or environment, including the city's legibility of a constructed (physical) context and the imageability of the city.

\footnotetext{
${ }^{a}$ Institute of Geography, Slovak Academy of Sciences, Bratislava, Slovakia (*corresponding author: J. Otahel, e-mail: otahel@savba.sk)

${ }^{\mathrm{b}}$ Department of Geography and Applied Geoinformatics, Faculty of Humanities and Natural Sciences, University of Presov, Slovakia

${ }^{\mathrm{c}}$ Eurosense, s.r.o., Bratislava, Slovakia

${ }^{\mathrm{d}}$ Swiss Federal Institute for Forest, Snow and Landscape Research WSL, Birmensdorf, Switzerland
} 
According to Morello and Ratti (2009), the differences are as follows: legibility is the clarity of the cityscape, and imageability is that quality in a physical object that gives it a high probability of evoking a strong image in any given observer. Dalton and Bafna (2003) use visual perception analysis to distinguish between imageability and intelligibility, highlighting the importance of the subject/ observer's visual perception. Put simply, imageability and intelligibility refer to the sequence of an observer's analysis of the image of a city, while legibility can be assessed by the primary visual perception of the physical condition of a city's monuments, connected with the analysis of visibility and viewshed. The physical state of a city as a primary object of visual perception can be assessed by objective criteria - in architecture (Benedikt, 1979; Rød and van der Meer, 2009) or in city planning (Batty, 2001), for example - to find the best places (points) to view selected monuments. An objective approach takes into account general, conventional knowledge of visual perception (Granö, 1929; Bell, 1999; Daniel, 2001; Sevenant and Antrop, 2007), using the conceptual foundations and synergetic tools of Geographic Information Systems (GIS) to analyse visibility and the visual qualities of a city (Nijhuis et al., 2011a; Van Lammeren, 2011; Garnero and Fabrizio, 2015; Fisher-Gewirtzman, 2016; Lin et al., 2017).

Is the selection of these viewpoints in terms of sightseeing trips sufficient, or is further evaluation required? These viewpoints should be analysed from the viewer's position in terms of visibility conditions and as a reflection of the viewer's (subject's) comprehensive sensorial effects. Lothian (1999) notes that the objectivist physical paradigm was part of the philosophy of the aesthetics of landscapes, but he concludes that landscape quality and its aesthetic assets are the results of the notion that landscape quality lies in the "eyes of the beholder," a notion derived from the subjectivist psychological paradigm. In this sense, a city's image has an objectivist dimension (size, shape, arrangement of buildings and objects), the architecture of the city in a spatial extent, and at the same time a city's image also has a subjectivist dimension (genius loci, architectural style, city life and rhythm) perceived by humans (individuals) in the time horizon (see Jacobs, 2011; Fisher-Gewirtzman, 2016). In a similar fashion, Nijhuis et al. (2011a) distinguish between the physiology of perception and the psychology of perception.

We will try to present visual perceptions in terms of both objective and subjective approaches, in order to compare the computational outcomes to the perceptual responses.

\section{Motives and aims}

The aims of this paper are to use the aforementioned approaches in an evaluation of the visual perceptions of the monuments of Bratislava's city centre (see Fig. 1). Representative monuments are interpreted as landmarks in Bratislava that are interesting for visitors and tourists in terms of the organisation of efficient sightseeing. We designed our research in an attempt to establish a connection between the objective and subjective perspectives of experiencing urban scenic quality; namely how the external aspect (physical condition) of the urban environment (legibility) might be combined with the subject's internal reception (imageability and intelligibility) of its scenic quality (Amedeo et al., 2009). The organisation of an effective visual contact requires knowledge of the visibility of monuments in terms of their physical arrangement in a city (urban fabric) as the primary prerequisite of visual perception (visibility conditions). It is also necessary to verify the quality of the visual perception of monuments and how these options of visibility (physical arrangement of the city) eventually influence the imageability (records of perceptions) and intelligibility (interpretation) of viewers regarding their particular perceptions.

The prerequisites for the convenient visual perception of selected monuments include viewpoints (observer points), places from which the monuments are visible, the distance to the observed monument, the visible side (legible, impressive), and the visible size (area) of the monument. Based on these prerequisites, answers to the following questions are sought:

- What are the practicable viewpoints from which observers can view the monuments?

- Where are the most attractive viewpoints of a relevant part of a monument being viewed from a certain distance according to measured/objective criteria?

The attractiveness of the viewpoints is understood in the context of the visibility (visual quality) of the seen monuments. The first step for visitors to construct a cognitive image of the physical disposition of a city is to analyse the visibility and visual qualities of monuments. This cognitive image is connected with the most important sense for visual analysis - eyesight. Its assessment is based on prerequisites that are close to the objectivist or physical paradigm for the cognition of quality (Lothian, 1999). An attempt to analyse them and to answer the questions according to the "measured/objective approach" (Daniel, 2001; Otahel', 1999; Nijhuis et al., 2011) are the first aim of this paper.

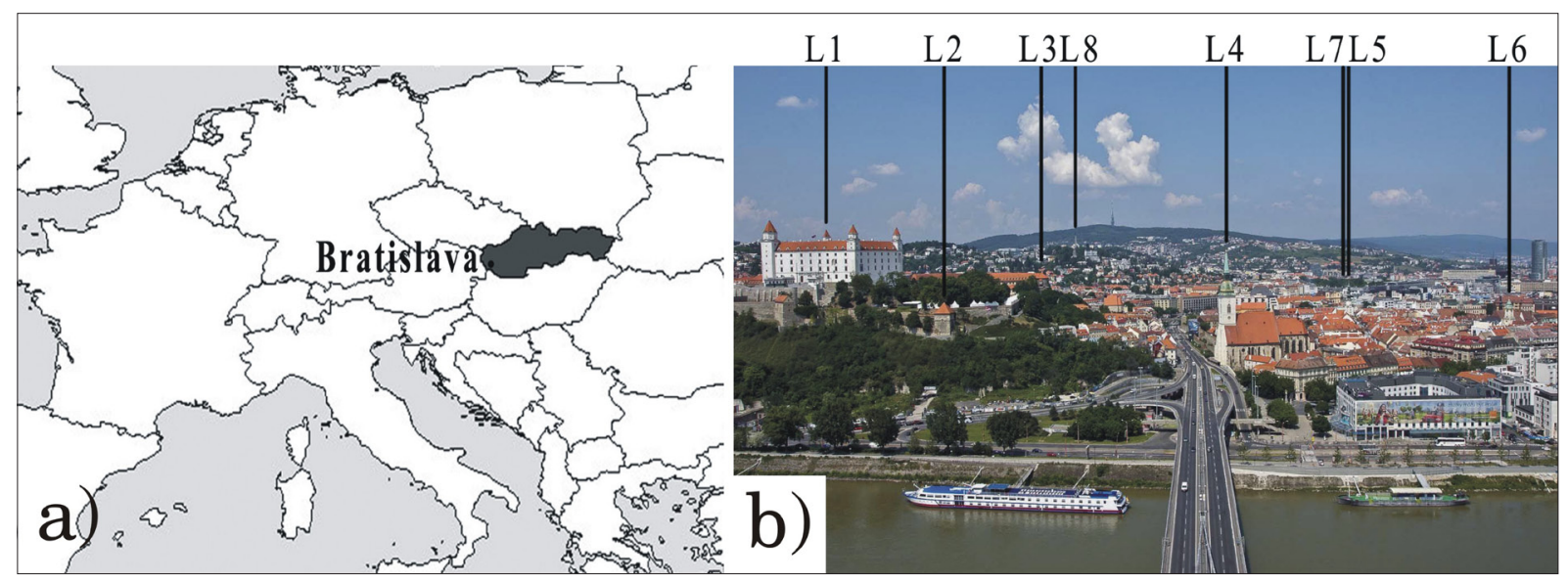

Fig. 1: Study area (a) location of Bratislava, (b) Bratislava city centre (L1-L8 landmarks, see the text) Source: authors' elaboration; photo: J. Lacika 
What are the imageability and intelligibility image of monuments and the city for visitors and inhabitants? The significance of a city's image is broader in connection with humans and their individualities, mental states, and behaviours (Bell, 1999; Daniel, 2001; Jacobs, 2011; Lothian, 1999; Nijhuis, Van Lammeren and Van der Hoeven, 2011; Saarinen, 1976), which specifically include the generally-accepted prerequisites of vision and complement the results of the visibility, viewshed, and visual quality of city analyses. They point to the significance both of the perceiving subjects and imply the inherent complexity of inhabitants and visitors, and also of the specificities of external conditions (e.g., the abovementioned physical elements, climatic conditions, and life in the city). These are the presumptions that motivated the analysis of the image of a city's monuments in terms of comprehensive perception, which entails a "behavioural/ subjective approach" (Daniel, 2001; Lothian, 1999; Nijhuis et al., 2011; Otahel', 2003) because "the subjectivist paradigm judges beauty from the interpretation by the mind behind the eyes" (Lothian, 1999, p. 178)

Hence, the second aim of this study is to evaluate the replies of respondents about their subjective perceptions of the city's monuments and to find answers to the following questions:

- Are the selected monuments actually impressive?

- Which city monuments are considered impressive by observers, and what is their order of significance?

- Which monuments do observers see from the selected viewpoints and places of enquiry?

- What is the judgement of observers of objectively-assessed viewpoints about which monuments are considered most attractive, and which do they consider to be the most attractive viewpoints?

We have tried to answer the following overall research question: Is there an agreement between the results obtained by visibility or visual quality analysis, according to a measured/objective approach, and the analysis of respondent perceptions, following a behavioural/ subjective approach, of the monuments of Bratislava city centre?

The third aim of this paper is more practical: to assess and compare the results of both approaches for finding the best places for sightseeing. Verification and delimitation of the best viewpoints are important prerequisites for realising effective sightseeing of selected city monuments.

\section{Materials and methods}

\subsection{Study area}

The study area in Bratislava comprises the Old Town and the wider Bratislava city centre (an area of approximately $2.5 \mathrm{~km}^{2}$ ). The selected monuments are notable for their historical and cultural value and are visible from several parts of the city due to their height, which is their dominant feature (see Figs. 1 and 2): Bratislava Castle (L1); Sigismund's Gate (L2); the Luginsland Bastion (L3); St. Martin's Cathedral (L4); St. Michael's Gate (L5); Old Town Hall (L6); the Presidential (Grassalkovich) Palace (L7); and Slavín (L8). This selection also respects the general consensus that arises from the authors' experiences and an overview of materials, including leaflets, websites and tourist guides that describe the interesting monuments of Bratislava.
In addition, Bratislava is a post-socialist city, characterised by the gradual development of new lifestyles, changes in demographic structure and behaviours, social and economic changes, the polarisation of society and technological changes. The development of the service sector especially affected the city centre, where specialised shops and financial and business services are concentrated. The development and redevelopment of real estate mainly brought about the revitalisation of historical buildings and a more-efficient use of space, including through tourism (Ira, 2003). One of the most distinctive, dominant features of the city is the castle built on top of the hill located close to the city centre, along with the castle walls, gates and bastions. Outer fortifications consisted of brick walls with two gunner bastions: Luginsland and Sigismund's Gate. The historical core of the city had city walls, including St. Michael's Gate, which was constructed around the $14^{\text {th }}$ century. St. Martin's Cathedral, which is a National Cultural Monument, was also built in the $14^{\text {th }}$ century and became the coronation church of the kings of Hungary in the $16^{\text {th }}$ century. The Old Town Hall and its tower dominate the square in the centre of the Old Town. Grassalkovich Palace, built beyond the Old Town in the $18^{\text {th }}$ century, is now the seat of the President of the Slovak Republic. Another dominant monument of Bratislava's centre is the Slavín military cemetery and monument to honour the Red Army soldiers who died in the effort to liberate the city in April 1945.

\subsection{Visibility analysis}

Visual analysis in the domain of physiognomic landscape research starts with a digital landscape model (DLM), which includes a digital terrain model (DTM) and a model of land cover (urban fabric, vegetation, etc.). A DLM uses numerous geometric attributes and indicators to describe the visual properties of the landscape or city (e.g. Nijhuis et al., 2011; Ode et al., 2008; Roos-Klein Lankhorst et al., 2011; Van Lammeren, 2011; Garnero and Fabrizio, 2015; Fisher-Gewirtzman, 2016; Lin et al., 2017). To analyse the geometry-related spatial characteristics of visible urban environments, we defined a set of all points visible from a given point in space. A similar concept of the so-called isovist was proposed by Benedikt (1979), who used 2D and 3D city models, DTM and GIS for measuring the visibility of urban spaces (Morello and Ratti, 2009; Nijhuis, Van Lammeren and Van der Hoeven, 2011). Viewshed polygons developed through isovist allow the calculation of the element's geometric properties (e.g. area, perimeter, number of vertices) and its abstraction in $2 \mathrm{D}$ space (Meilinger et al., 2012). In general, the visibility of urban spaces is determined by the viewer's physical circumstances: viewpoint and visible field (viewshed), delimited isovists, and lines of sight (Fisher, 1995).

Several authors (e.g. Bishop, 2003; de Floriani et al., 1994; Kidner et al., 1997; Llobera, 2003) dealt with the application of landscape visibility and urban elements. Other examples can be found in terms of city planning (Batty, 2001), architecture (Benedikt, 1979; Rød and van der Meer, 2009), landscape planning (Fisher, 1995), tourism (Fyhri et al., 2009) and landscape aesthetics (Nijhuis, 2011; Janečková Molnárová et al., 2017). The physical disposition of the city (particularly the terrain, urban fabric, greenery, traffic signs, advertising boards, etc.) modifies the isovist field (viewshed). A visual quality analysis will be attempted in this study by defining the particular conditions and application of the abovementioned tools. 
Visibility is limited by the physical disposition (urban fabric) and terrain of the city. Another prerequisite is the analysis of the optimal distance of the view between the observer and the selected monuments (Bertamini et al., 1998). Digital datasets (EUROSENSE Ltd.) generated by methods of aerial photogrammetry were used in this study, including the stereoscopic DTM, which comprises a network of altitude points and terrain edges, a 3D digital building model comprising polygons of roofs, and orthophotomaps from 2008 with a pixel size of $25 \mathrm{~cm}$. An ESRI ArcGIS desktop v9.0 with 3D Analyst extension was used in all auxiliary operations. Computation of the visibility of selected landmarks was processed in the GRASS GIS using the r.los statement (GRASS Development Team, 2010). The

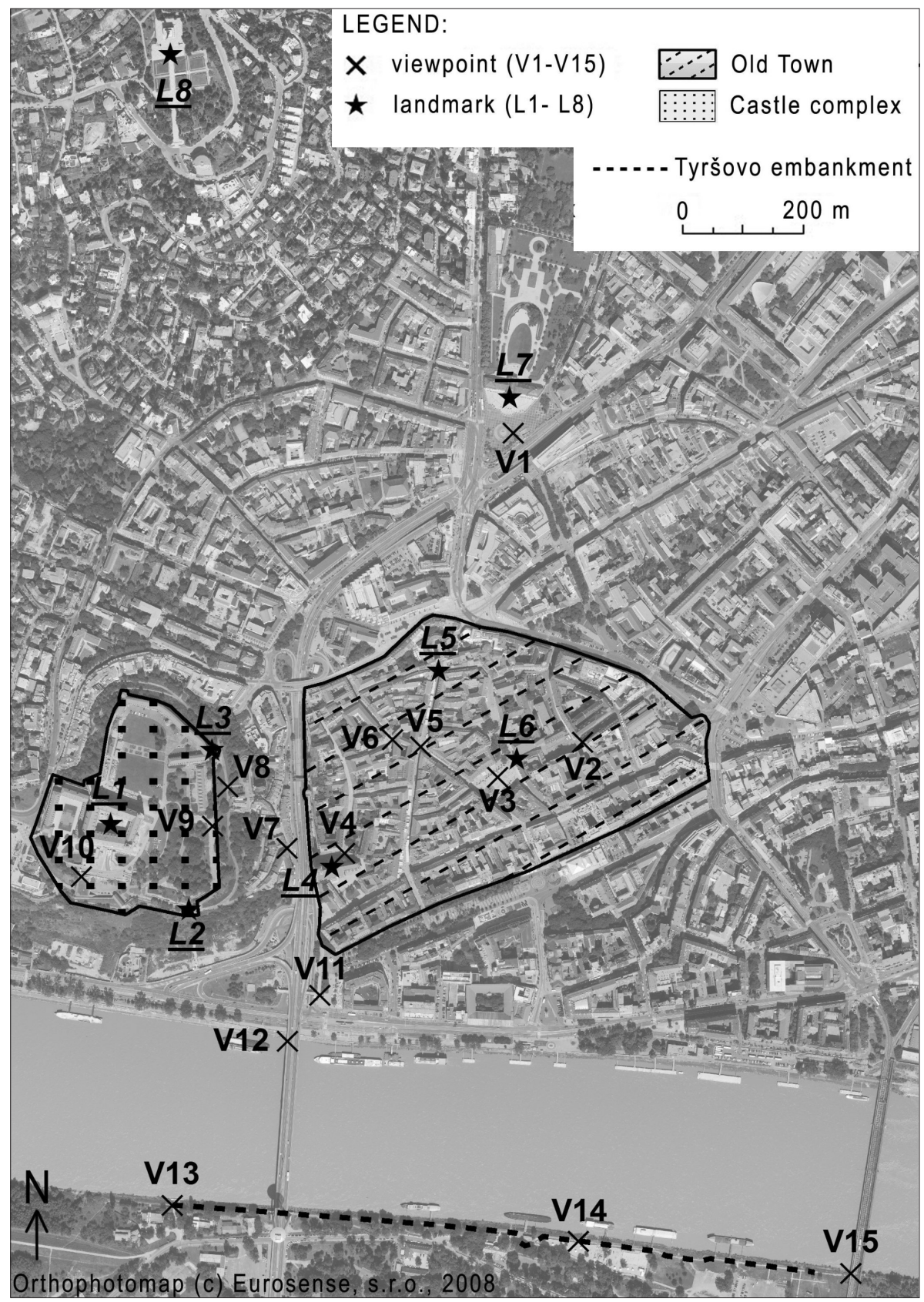

Fig. 2: Study area, location of viewpoints and landmarks

Source: authors' elaboration; Ortophotomaps 2008 드 Eurosense, Ltd.

\begin{tabular}{cccc}
\hline & Criteria of visibility & & \\
\cline { 1 - 2 } Distance from monument & Side of monument & Visible size of monument & Attractiveness of viewpoints/score \\
\hline$<100 \mathrm{~m}$ & front & entire & 4 - very attractive \\
$<100 \mathrm{~m}$ & rear & at least one third & \\
$100-1,200 \mathrm{~m}$ & front/rear & at least one third & \\
$>1,200 \mathrm{~m}$ & front/rear & at least one third & \\
\hline
\end{tabular}

Tab. 1: Attractiveness of viewpoints according criteria of monument visibility Source: authors' elaboration 
environment requires the adaptation of data entry to what is referred to as a 3DLM, which contains a DTM raised by $165 \mathrm{~cm}$ - the average level of an observer's eyes (Hlavatá and Otahel', 2010) - and a 3D model of buildings. Other barriers (greenery, traffic signs, advertising billboards, etc.) were not included in the DLM or, consequently, in the visibility analysis.

The viewshed was analysed and measured in the GIS using the 3DLM, which includes the DTM and a bird's-eye model of the roofs of buildings in the city. The computation of r.los considers DLM, which takes into account only DTM and shading by existing buildings, that is, the places or viewpoints from which a walking tourist can expect to see the monuments and places from which the monuments cannot be seen. Those viewpoints were classified as uncertain viewpoints (Fig. 3). Viewpoints that were accessible to the walking public were classified as verified viewpoints (Fig. 3). Each viewpoint is represented by a $1.5 \times 1.5 \mathrm{~m}$ square (approximately $2.25 \mathrm{~m}^{2}$ ). The attractiveness of each selected viewpoint (places of enquiry, V1-V15, see Fig. 2) was assessed in GIS according to the criteria of the visibility of monuments (see Tab. 1) in terms of comprehensive visual perception.

The attractiveness of the viewpoints actually represents the conditions of visibility (visual quality) with respect to the contemplated monuments. This included the distance from the monument, the view of the impressive side of the monument, the visible size of the monument (Granö, 1929; Nijhuis et al., 2011; Sevenant and Antrop, 2007; Garnero and Fabrizio, 2015), and the number of visible monuments. To determine what would be considered very attractive, for example, we assessed viewpoints less than $100 \mathrm{~m}$ from specific locations and from which a view of an entire monument from the front (impressive) side was possible. For very attractive viewpoints, we also used the precondition of the distance of visual perception with respect to the effect of central vision, which comprises the inner $30^{\circ}$ of an observer's vision (Spector, 1990) or the highest degree of acuity (Nijhuis et al., 2011). We found such an approach especially important in searching for an optimal proximity to the monument, depending on its height. A very attractive viewpoint would be one in which the entire monument is seen in a visual cone of $30^{\circ}$ and the distance of optimal visual perception can be up to about $100 \mathrm{~m}$ (Fig. 4).

If a viewpoint satisfies the distance criterion of less than $100 \mathrm{~m}$ and at least one-third of the monument is seen from the rear side, then it was assessed as medium attractive. In addition, we also analysed a farther-away "landscape" of a distance of more than 1,200 metres as the limit for perceiving an object with the naked eye (Granö, 1929; Nijhuis et al., 2011; Sevenant and Antrop, 2007). If a viewpoint is at a distance of more than $100 \mathrm{~m}$ and less than 1,200 $\mathrm{m}$ and at least one-third of the monument is seen, then it was assessed as little attractive; if it is at a distance of more than $1,200 \mathrm{~m}$, then it was assessed as very little attractive (Tab. 1). The individual attractiveness grades were assigned scores from 1 (very little attractive) to 4 (very attractive), and the resulting score was computed for all viewpoints (V1-V15) as the sum of multiples of the viewpoint attractiveness score (1-4) by the number of visible monuments (L1-L8).

\subsection{Research on perception of a city's monuments}

Human perception of a landscape or city is subjective and connected with each person's particular individuality. Nijhuis et al. (2011) differentiate the approaches to landscape perception in four paradigms and two types of models, drawing upon works by Zube et al. (1982), Lothian (1999), and Daniel (2001). The first type, called expert models, represents a typical approach to the study of human perception from the classic work of Lynch (1960). The psychophysical approach is one of three approaches of a second type of model: public preference (Nijhuis et al., 2011). This approach for testing general public perceptions of a landscape or city is a typical behavioural approach that addresses emotional, sensorial and intuitive individual perceptions and imaginations (Appleton, 1975; Cañas et al., 2009; Daniel, 2001; Lothian, 1999; Otahel', 2003; Saarinen, 1976; Fisher-Gewirtzman, 2016).

Research on city perceptions with respect to visitors and inhabitants is very important for urban tourism, which is one among many social and economic forces in urban environments (Ira, 2003). As travel has grown enormously and continuously over the past 20 years in post-communist cities (Church and Coles, 2007), many urban areas are attracting more visitors. In particular, there is high demand for tourism related to the architecture, social activities, and historical and cultural monuments in cities. The visitor preferences are usually evaluated using visitor surveys, which ask tourists about what they actually do. These surveys consistently reveal the popularity of rather vaguelyarticulated activities, such as "sightseeing", "wandering about", "taking in the city" and "getting among the people" (Ashworth and Page, 2011). These activities give opportunities for city-perception research, especially for finding the best places for seeing a city's monuments.

In our research, surveys were conducted in on-site interviews about visitors' perceptions. Interviews enabled us to collect data on residents' and visitors' perceptions of
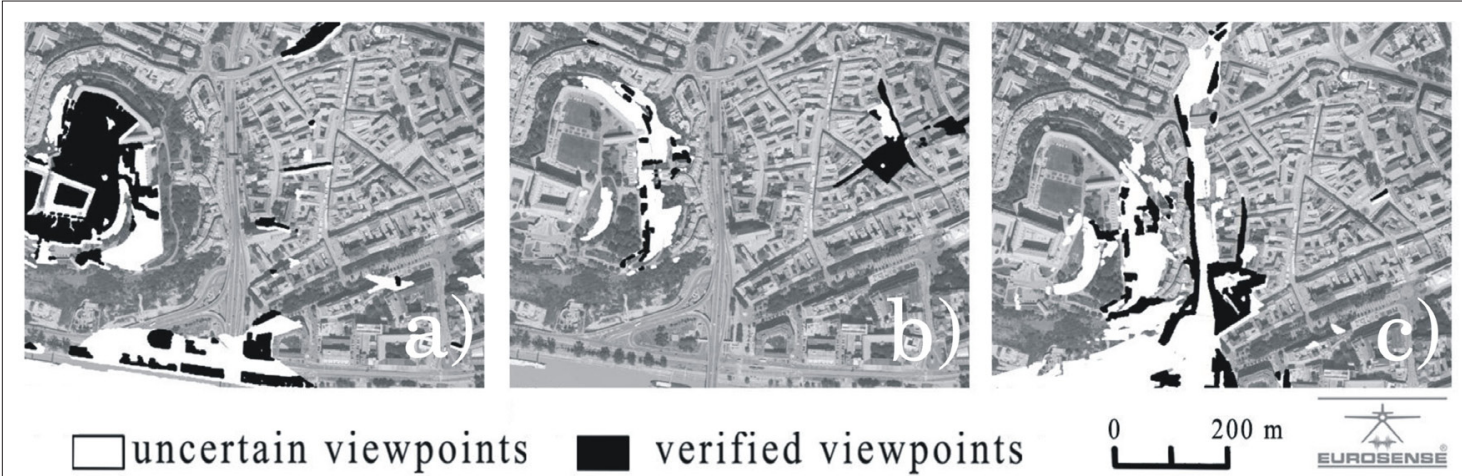

Fig. 3: Uncertain and verified viewpoints to see: (a) Bratislava Castle, (b) Old Town Hall, (c) St. Martin's Cathedral Source: authors' elaboration; Ortophotomaps 2008 @ Eurosense, Ltd. 
historical and cultural monuments in Bratislava. The survey included questions related to selected places and reasons for visiting, the frequency of their visits, and the attractiveness of the view of individual monuments. Visitors were also asked to rank representative locations and the attractiveness of places and monuments in the city of Bratislava (selected questions are in Tab. 2). The survey questions were developed from experience gained from focus group meetings conducted prior to designing the questionnaire. Respondents were interviewed in person. On-site surveys were conducted in the 15 selected localities near or farther away from monuments, specifically at viewpoints V1-V15 (Fig. 2: for location name see Tab. 3) in the city centre. Respondents who participated in the survey were asked to rate the attractiveness of views of the selected monuments from the selected viewpoints: little attractive, medium attractive, and very attractive. The questionnaire was asked of a sample of 305 respondents, stratified according to gender and age, about the different localities related to the 15 selected viewpoints. IBM SPSS Statistics 21 (2011) statistical software was used in the analysis.

\section{Results}

\subsection{Results of the visibility analysis}

Uncertain viewpoints (water surfaces, private plots, floors of buildings, and transport communications) were verified in the terrain and were selected as verified viewpoints only if they were accessible to the walking public (Fig. 3).

The attractiveness of the visibility of selected monuments was evaluated only for verified viewpoints and for various visual qualities (Fig. 4). Flat determination of the ideal observation distance from a monument does not take into account the size (height) of the observed monument and conditions of the surrounding terrain in terms of relief and the urban fabric. For that reason, a "line of sight" with a viewpoint on its circumference from which the whole monument is observable under a $30^{\circ}$ vertical angle (the most ideal view in terms of eye optics and perception) was computed for each monument.

The "line of $30^{\circ}$ vertical view angle" runs at different distances from the monument in relation to the relief and urban fabric (see Fig. 4). The attractiveness of verified
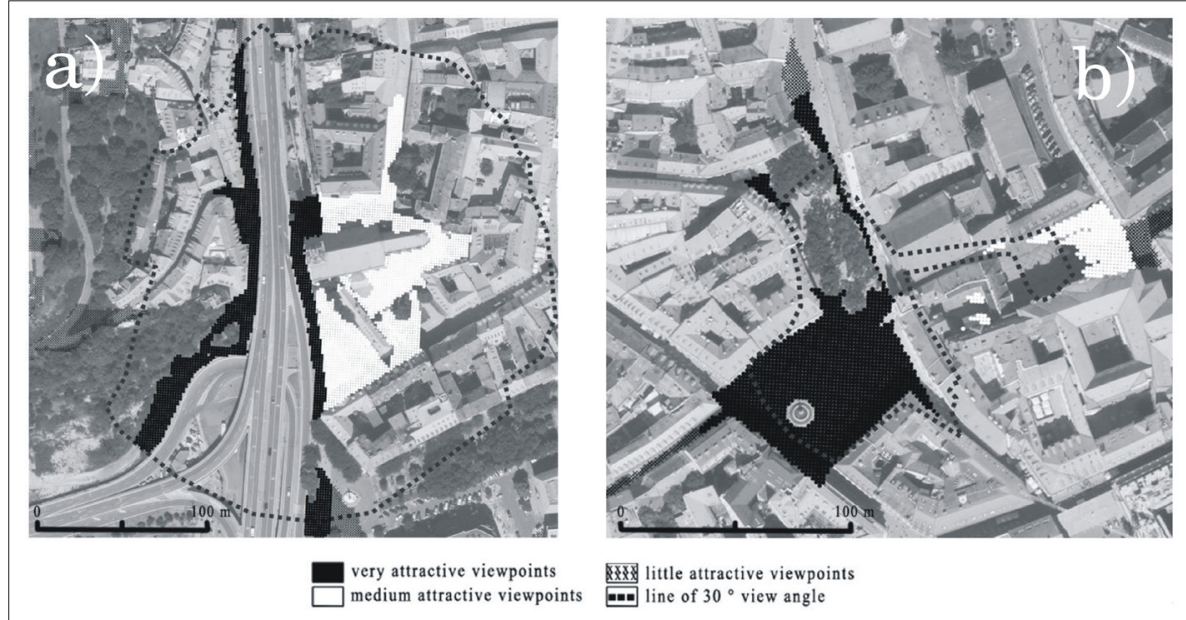

Fig. 4: Attractiveness of viewpoints (a) views of St. Martin's Cathedral, (b) views of Old Town Hall Source: authors' elaboration; Ortophotomaps 2008 (c) Eurosense, Ltd.

\begin{tabular}{|c|c|c|c|}
\hline $\begin{array}{l}\text { Viewpoint } \\
\text { No. }\end{array}$ & $\begin{array}{l}\text { Question } \\
\text { No. }\end{array}$ & Question & Replies (in \%) \\
\hline V1-V15 & 1 & Reason of visiting this place? & $\begin{array}{l}\text { I spend my leisure time here }-31.1 \text {, Tourist }-32.1 \text {, } \\
\text { Passer-by - } 35.7\end{array}$ \\
\hline V1-V15 & 2 & How often do you visit this place? & $\begin{array}{l}\text { Regularly }-27.2 \text {, From time to time }-24.6 \text {, } \\
\text { Seldom }-25.2 \text {, First time I am here }-23.0\end{array}$ \\
\hline V1-V15 & 3 & $\begin{array}{l}\text { Does this place offer a nice view of interesting } \\
\text { monuments of Bratislava? }\end{array}$ & $\begin{array}{l}\text { Positive replies of all respondents - V1(31.8), } \\
\text { V2(85.4), V3(90.9), V4(47.4), V5(80.0), V6(56.5), } \\
\text { V7(60.0), V8(55.0), V9(52.2), V10(10.0), V11(61.9), } \\
\text { V12(60.0), V13(60.0), V14(85.7), V15(94.4) }\end{array}$ \\
\hline V1-V15 & 4 & $\begin{array}{l}\text { Which of representative cultural or historical objects } \\
\text { of Bratislava do you recommend to see to a visitor? }\end{array}$ & $\begin{array}{l}\text { L1(49.7), L4 (11.6), L8 (8.8), Devín (5.3), L5 (3.2), } \\
\text { National Theatre (3.4), L7 (2.9), and Primatial } \\
\text { Palace (2.3) }\end{array}$ \\
\hline V1-V15 & 5 & $\begin{array}{l}\text { Order representative cultural and historic objects of } \\
\text { Bratislava according to importance. }\end{array}$ & $\begin{array}{l}\text { Replies of all respondents - L1 (58.7), L4(10.8), L8 } \\
\text { (6.9), Devín (5.0), Slovak National Theatre (3.2), L5 } \\
\text { (2.9), L7 (2.6), and Primatial Palace (1.3) }\end{array}$ \\
\hline V1-V15 & 6 & $\begin{array}{l}\text { Is the Castle (L1) one of representative monuments } \\
\text { of Bratislava? }\end{array}$ & $\begin{array}{l}\text { Yes - } 96.4 \text { all respondents: } 95.2 \text { inhabitants of } \\
\text { Bratislava: } 100.0 \text { visitors from surroundings less } \\
\text { than } 50 \mathrm{~km}: 96.0 \text { living outside Bratislava }\end{array}$ \\
\hline V1-V15 & $7-13$ & $\begin{array}{l}\text { Is the } \mathrm{L} 2(\mathrm{~L} 3, \mathrm{~L} 4, \mathrm{~L} 5, \mathrm{~L} 6, \mathrm{~L} 7 \text {, and } \mathrm{L} 8 \text { ) one of the } \\
\text { representative monuments of Bratislava? }\end{array}$ & $\begin{array}{l}\text { L2 yes - 28.9, (L3 - 26.2, L4 - 91.8, L5 - 77.4, L6 - } \\
52.1, \text { L7 - 85.9, L8 - 76.1) }\end{array}$ \\
\hline
\end{tabular}

Tab. 2: Interpretation of respondents' replies to selected questions (V1-V15; for names of monuments L1-L8, see text; location in Fig. 2.). Source: authors' elaboration 
viewpoints was assessed using the objective criteria of comprehensive visual perception (see Tab. 1). Distances within $100 \mathrm{~m}$ from each monument were differentiated as very attractive and medium attractive viewpoints and were graphically indicated (see Fig. 4). The highest values of attractiveness included the following viewpoints as places of enquiry: V1, V2, V3, V4, V5, V7, V8, V10 and V11. Viewpoints from greater distances than $100 \mathrm{~m}$ have been assessed as little attractive and very little attractive and included the following places of enquiry: V6, V9, V12, V13, V14 and V15 (see Tab. 3).
All 15 selected viewpoints (places of enquiry) were evaluated further by the number of visible monuments and the criteria of visibility (Tab. 1). Analyses showed that Bratislava Castle is the most-exposed monument because it is visible from 10 viewpoints, St. Martin's Cathedral is the second most-visible with visibility from nine viewpoints, and the Presidential Palace is the least exposed because it can be seen from only two viewpoints (Fig. 5a). The final score of visibility conditions (visual quality) of all 15 selected viewpoints ranged between 2 and 12 (see Tab. 3).

\begin{tabular}{|c|c|c|c|c|c|c|}
\hline \multirow{2}{*}{$\begin{array}{l}\text { Viewpoint } \\
\text { No. }\end{array}$} & \multirow{2}{*}{ Location } & \multicolumn{5}{|c|}{ Value of attractiveness and number of monuments } \\
\hline & & Very-4 & Medium-3 & Little-2 & Very little-1 & Total \\
\hline $\mathrm{V} 1$ & In front of the Presidential Palace & 1 & 0 & 3 & 0 & 10 \\
\hline $\mathrm{V} 2$ & Primate's Square & 0 & 1 & 0 & 0 & 3 \\
\hline V3 & Hlavné Square & 1 & 0 & 1 & 0 & 6 \\
\hline V4 & Outside St Martin's Cathedral & 0 & 1 & 1 & 0 & 5 \\
\hline V5 & $\begin{array}{l}\text { Michalská St. } \\
\text { (intersection of Sedlárska St. and Ventúrska St.) }\end{array}$ & 1 & 0 & 0 & 0 & 4 \\
\hline V6 & Subway of the University Library & 0 & 0 & 1 & 0 & 2 \\
\hline V7 & In front of the House of the Good Shepherd & 1 & 0 & 0 & 0 & 4 \\
\hline V8 & Below the Luginsland bastion & 1 & 0 & 3 & 0 & 10 \\
\hline V9 & Lower Castle terrace & 0 & 0 & 6 & 0 & 12 \\
\hline V10 & $\begin{array}{l}\text { Terrace before the entry to the Castle } \\
\text { (panoramic view of the Danube and Petržalka) }\end{array}$ & 1 & 0 & 0 & 0 & 4 \\
\hline V11 & $\begin{array}{l}\text { Terrace staircase leading to the Bridge } \\
\text { of the Slovak National Uprising }\end{array}$ & 1 & 0 & 2 & 1 & 9 \\
\hline $\mathrm{V} 12$ & New Bridge (bicycle lane over the Danube) & 0 & 0 & 2 & 0 & 4 \\
\hline V13 & Boatyard (right bank of the Danube) & 0 & 0 & 3 & 0 & 6 \\
\hline V14 & Au Cafe (Tyršovo Embankment) & 0 & 0 & 5 & 1 & 11 \\
\hline $\mathrm{V} 15$ & Old Bridge & 0 & 0 & 1 & 4 & 7 \\
\hline
\end{tabular}

Tab. 3: Attractiveness of viewpoints (V1-V15, location in Fig. 2) according to visibility of monuments Source: authors' elaboration

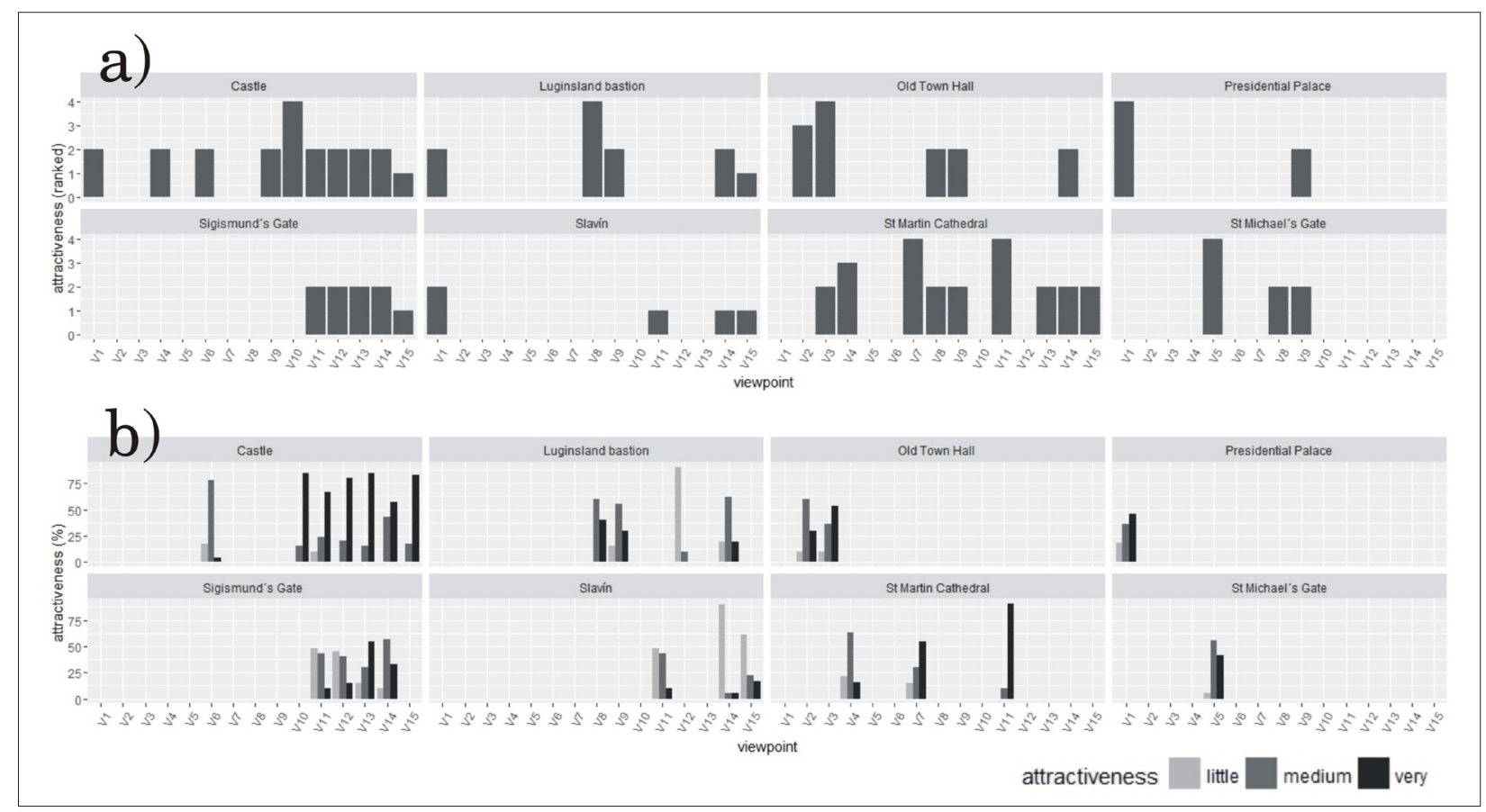

Fig. 5: Attractiveness of viewpoints (V1-V15, location in Fig. 2) (a) according visibility of monuments, (b) according respondents' perception of monuments. Source: authors' elaboration 


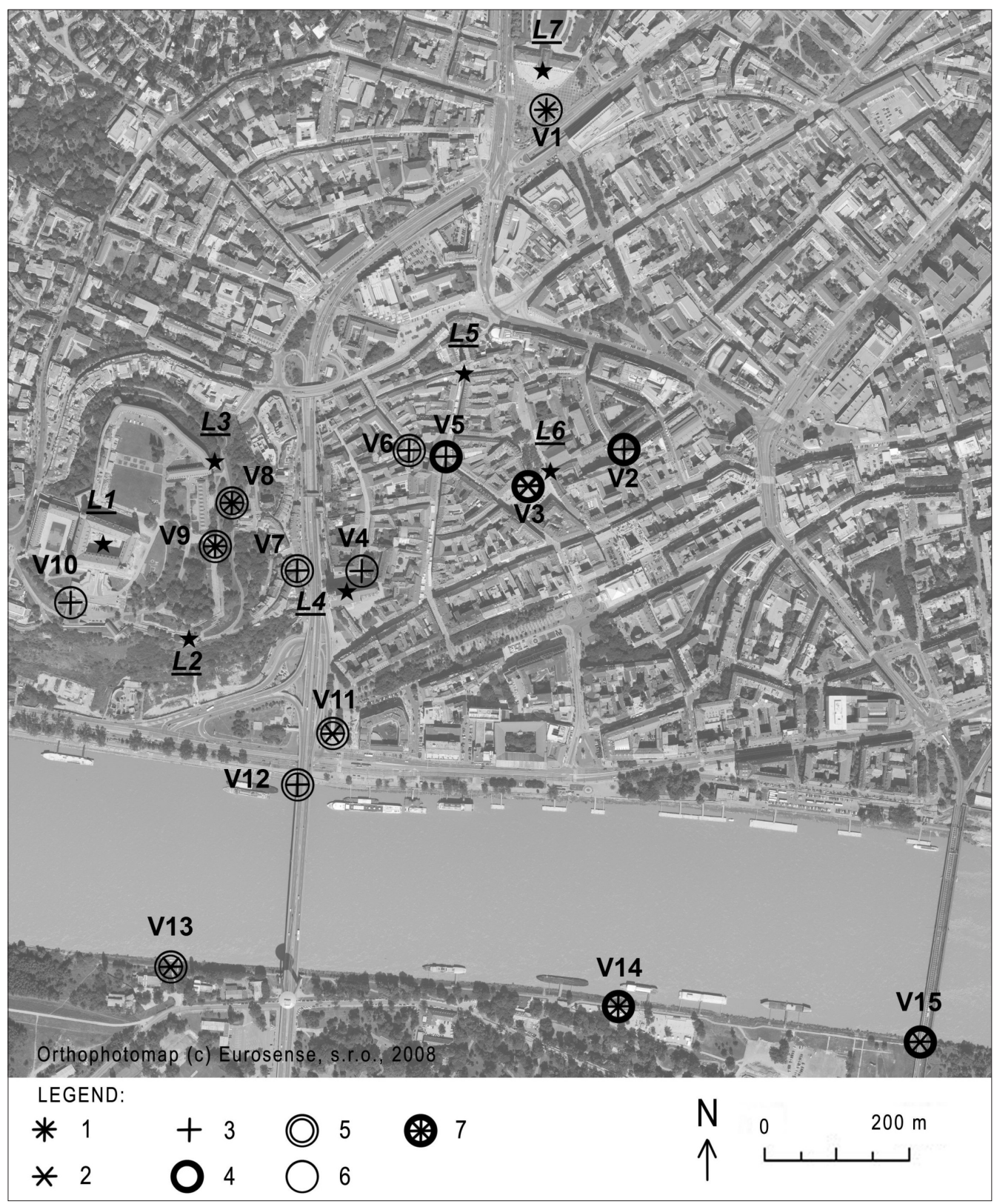

Fig. 6: Assessment of viewpoints (V1-V15, see Tab. 3) according to the visibility conditions and respondents' perception of city's monuments for identification of the best sightseeing places. Legend: 1 - best visibility conditions, 2 - medium visibility conditions, 3 -worst visibility conditions, 4 - best quality perception, 5 - medium quality perception, 6 - worst quality perception, 7 - assessment according to both approaches (example viewpoint V14 - with the best visibility conditions and best quality perception)

Source: authors' elaboration, Ortophotomaps 2008 ㄷ Eurosense, Ltd.

\begin{tabular}{ll}
\hline Way of assessment & Value of viewpoints (in score and \%) \\
\hline $\begin{array}{l}\text { Objective approach (visibility of monuments) } \\
\text { Best conditions of visibility (score } \geq 10 \text { ) }\end{array}$ & $\mathrm{V} 1(10), \mathrm{V} 8(10), \mathrm{V} 14(11), \mathrm{V} 9(12)$ \\
Medium conditions of visibility (score 6 - 9) & $\mathrm{V} 3(6), \mathrm{V} 13(6), \mathrm{V} 15(7), \mathrm{V} 11(9)$ \\
Worst conditions of visibility (score $\leq 5)$ & $\mathrm{V} 6(2), \mathrm{V} 2(3), \mathrm{V} 5(4), \mathrm{V} 7(4), \mathrm{V} 10(4), \mathrm{V} 12(4), \mathrm{V} 4(5)$ \\
Subjective approach (perception of monuments) & \\
Above average rate of positive replies $(>80 \%)$ & $\mathrm{V} 5(80.2), \mathrm{V} 2(85.4), \mathrm{V} 14(85.7), \mathrm{V} 3(90.9), \mathrm{V} 15(94.4)$ \\
Average rate of positive replies $(50-80 \%)$ & $\mathrm{V} 9(52.2), \mathrm{V} 8(55.0), \mathrm{V} 6(56.5), \mathrm{V} 7(60.0), \mathrm{V} 12(60.0), \mathrm{V} 13(60.0), \mathrm{V} 11(61.9)$ \\
Below average rate of positive replies $(<50 \%)$ & $\mathrm{V} 10(10.0), \mathrm{V} 1(31.8), \mathrm{V} 4(47.4)$ \\
\hline
\end{tabular}

Tab. 4: Attractiveness of viewpoints (V1-V15, see Tab. 2) according visibility and respondents' perception of monuments, location in Fig. 2.

Source: authors' elaboration 
Attractiveness of viewpoints (V1-V15) was computed as the sum of multiples of the viewpoint attractiveness score (four categories, see Tab. 1) by the number of visible monuments. All viewpoints were classified into three groups according to the obtained total score (Tab. 3). Viewpoints V2, V4, V5, V6, V7, V10 and V12 obtained a score $\leq 5$ and were assessed as having the worst conditions of visibility (Fig. 6). The medium conditions of visibility (score 6-9) applied to viewpoints V3, V11, V13 and V15, while the best conditions of visibility with a score $\geq 10$ are related to viewpoints V1, V8, V9 and V14.

Viewpoints V6 (score 2) and V3 (score 3) were assessed as the least attractive places, with the lowest scores of the city's monument visibility conditions, while viewpoints V14 (score 11) and V9 (score 12) were assessed as places with the best visibility conditions of all selected monuments of the city (Tab. 4, Fig. 6).

\subsection{Results of visitors' perceptions}

The sample of respondents $(\mathrm{n}=305)$ comprised inhabitants, tourists and visitors, asking about their perceptions of the city's monuments. Specifically, we surveyed visitors (visitors from neighbouring municipalities up to $50 \mathrm{~km}$ away $-17.7 \%$, and visitors outside Bratislava $-40.7 \%$ ), and residents of Bratislava (41.3\%). Regarding the demographic characteristics of the respondents, the average age was $33.2,13.2 \%$ of respondents had primary, $45.2 \%$ secondary, and $41.6 \%$ higher education, and the survey sample consisted of $50.2 \%$ male and $49.8 \%$ female. The reasons for visiting the place of contact with the respondents (one of the viewpoints and simultaneously the place of the on-site interview) were split into approximately equal thirds: spending leisure time; being a tourist; or being a passer-by. The frequency of visits was classified into four categories (see Tab. 2).

For the most significant results of the questionnaire, we considered the replies to question No. 3: whether the viewpoint offers nice views of interesting monuments in Bratislava. In total, $65.2 \%$ of all respondents referred to all 15 places as those with nice views. Positive replies of all respondents distinctly differed according to the place of questioning (see Tab. 2, Question No. 3). Finally, responses were divided into three groups. (see Tab. 4). The first group contains viewpoints V10 (the lowest rate of $10.0 \%$ ), V1 and V4, with a distinctly below-average rate of positive responses (less than 50\%), and it represents viewpoints with the worst quality of perception as assessed by the subjective approach (see Fig. 6, Tab. 4). Viewpoints V9, V8, V6, V7, V12, V13 and V11 (50-80\% positive replies) represent the group with medium quality of perception. The third group consists of viewpoints V5, V2, V14, V3 and V15 (the highest rate of $94.4 \%$ ) with distinctly above-average rates of positive replies (over 80\%) and the best quality of perception (see Fig. 6, Tab. 4).

The questions concerning the representative monuments of Bratislava and the order of their significance were used for finding the best places for sightseeing. With regard to question No. 4, almost one half of respondents (49.7\%) recommended that potential visitors see the Castle (L1) as a representative, cultural and historical monument. Approximately one-tenth of respondents mentioned St. Martin's Cathedral in second place, and Slavín in third place (see Tab. 2). As far as the sample of respondents' ranking of monuments (question No. 5), the Castle was afforded the first place (58.7\% of respondents), followed by St. Martin's Cathedral, Slavín, Devín, the Slovak National Theatre, St. Michael's Gate, the Presidential Palace, and the Primatial Palace (see Tab. 2).

Additional important results of respondent perceptions were analysed in terms of replies to the question about what type of view of a particular monument is offered by a given viewpoint (Fig. 5b). Most respondents gave high marks to the St. Martin Cathedral from viewpoint V11 (90.5\%), and the Castle from viewpoints V10 (85.0\%), V13 (85.0) and V13 (83.3\%). A high percentage of respondents also reported that the view of Slavín from viewpoint V14 is little attractive (90.5\%, see Fig. 5b).

\begin{tabular}{cll}
\hline Viewpoint No. & What disturbs & What pleases \\
\hline V1 & Traffic, noise, smog, scruffy environment & Place to relax, a fountain, architecture \\
V2 & Scruffy buildings, advertisements & Quiet place, greenery \\
V3 & Tourists & Fountain, coffeehouses, silence, peaceful atmosphere \\
V4 & Scaffolding, road, traffic & Greenery, historical nature \\
V5 & Waiters & Good environment, atmosphere, historical buildings \\
V6 & Billboards, posters & Castle \\
V7 & Cars, rush, refurbishment of the Cathedral & View of historical centre, relative tranquillity \\
V8 & Cars & View, silence, history \\
V9 & Trees impeding the view & View of the city, panorama \\
V10 & Petržalka (large-scale housing estate) & Panorama \\
V11 & Noise, traffic on the New Bridge, refurbishment of the & Night lighting of the Cathedral and Castle \\
& Cathedral & \\
V12 & Busy roads, crossroads, bridge & River Danube, view of Castle and Petržalka \\
& & (large-scale housing estate) \\
V13 & Unkempt areas, neglected greenery, scaffolding & Castle, Cathedral, river, greenery \\
V14 & Gallery, unkempt areas, scaffolding, building site & Historical buildings, Castle, river, greenery \\
V15 & Gallery, unkempt embankment, Old Bridge, port & Castle, historical buildings, river, greenery, Old Town \\
\hline
\end{tabular}

Tab. 5: Interpretation of respondents' replies regarding the quality of viewpoints Source: authors' elaboration 
Comparing the results of both approaches (see Tab. 4), there was found a significant relationship in the assessment of the viewpoint V14 (Tab. 4) between the best visibility conditions (score 11) and the best quality of perception (85.7\%) and in the assessment of viewpoint V10, which had low measured visibility conditions (score 4) and the worst quality of respondents' perception (10.0\%). In the assessment of the most other viewpoints no significant relationship was found. The results of both approaches represent a comprehensive way of defining and verifying the best places for effective sightseeing of the city's monuments (see Fig. 6).

\section{Discussion}

The results of the visibility analysis indicate the optimal viewpoints of comprehensive visual perceptions regarding the distance, the visible side in terms of legibility and impressiveness, size (height), and the number of visible monuments. Justification for this approach is found mainly in the evaluation of visibility conditions, such as with city buildings in the works of architects and urban planners, for example Benedikt, 1979; Batty, 2001; Rød and van der Meer, 2009; Garnero and Fabrizio, 2015; FisherGewirtzman, 2016; and Lin et al., 2017; or in the physiognomic landscape research of landscape architects, such as Nijhuis, 2011; Ode et al., 2008; and Van Lammeren, 2011. An important question, however, is whether the visibility conditions (visual perception) of the city monuments are sufficient in terms of other more subjective aspects of perception (see Daniel, 2001; Jacobs, 2011; Lothian, 1999; Nijhuis et al., 2011), and mainly in the context of tourist interest (Fyhri et al., 2009; Zemła, 2016)? To answer this question, we looked to the results of the second part of our research, in which we used the objective approach to compare and verify our interpretation of the responses to the questions from the on-site interviews.

The viewpoints ranked most highly by the objective approach were viewpoints V1, V8, V9 and V14 (Fig. 5a, Tab. 3). Viewpoint V1 (score 10) is, according to respondents, one with the worst quality of perception $(31.8 \%$, Tab. 2, Fig. 5b). This indicates that not all visitors and tourists also appreciated the number of visible monuments (see Tab. 3), because they may not have known where Slavín (L8) and Luginsland (L3) were located. The benefit of visibility analysis, however, is the complexity of evaluation it affords for all conditions of selected monuments. The low ranking of respondents' perception for viewpoint V1 is probably due to the noise and disturbance of nearby transport (see Tab. 5). The psychology of perception is mainly influenced by biological and individual perception factors (Jacobs, 2011). An exception from this assumption is the view of the Presidential Palace, which was evaluated by most respondents as very attractive (45.5\%, Fig. 5b).

Viewpoint V9 (score 12) ranks best according to the objective approach to visibility analysis. From that viewpoint, tourists can spot the Castle (L1), the bastion (L3), and four additional monuments in the city centre (L4, L5, L6 and L7), although, because of the distance, the visible parts of the monuments were evaluated as little attractive; viewpoint V9 also provides a panoramic (comprehensive) view of the historic core (the Old Town). Sightseeing from this location requires some knowledge of the history of monuments and their locations in the city, so that it might be more important for locals or guided groups. This approach and ranking also determine the significance of the viewpoint regarding the efficient, albeit "distant", sightseeing of Bratislava that it affords. An analysis of respondent perception according to the subjective approach showed that the viewpoint is of medium quality $(52.2 \%$, Tab. 2). This ranking was certainly also affected by the influence of trees that impede the view (Tab. 5). Conversely, the benefits of viewpoint V9 might be the freedom that visitors have to move along the whole terrace and the chance to locate the best views of the Old Town that are devoid of the disruptive effect of greenery. According to the subjective analysis of respondent perception, V11 offers the best view of the St. Martin Cathedral (90.5\%, Fig. 5b), but only a medium-quality perception (61.9\%, Tab. 2), which was probably affected by the disruptive effect of the traffic noise on the bridge (see Tab. 5).

Viewpoint V14 was second best for visibility conditions because it captures five monuments (L1, L2, L3, L4 and L6) and the distant Slavín (L8, see Tab. 3 and Fig. 5a). Respondents appreciated the calm spot on the bank of the River Danube, which offers a nice view of the Castle and the historic city core, and they conferred on it a third place ranking (85.7\%, Tab. 2).

Viewpoints in the historic core do not offer as many chances to see the selected monuments, but they do disclose other historic buildings, as appreciated by tourists (see Zemła, 2016). Viewpoint V3 is evaluated as medium
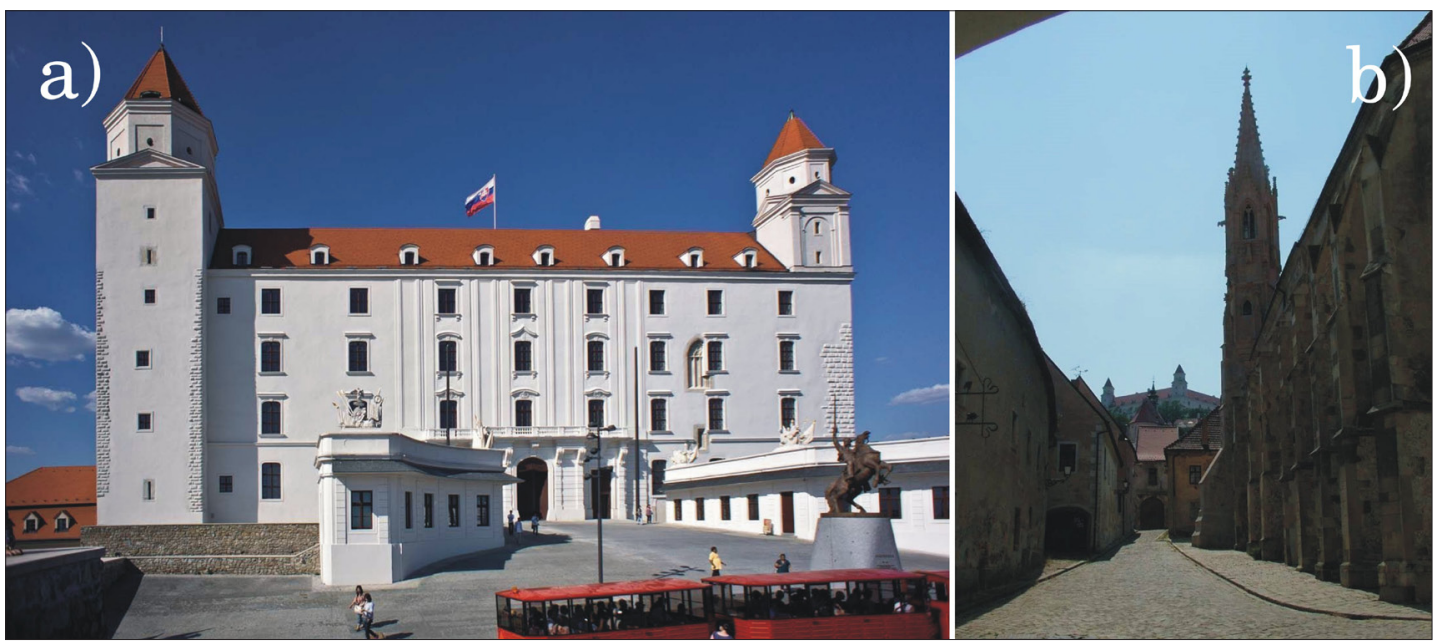

Fig. 7: (a) View of Castle from viewpoint V10, (b) Views of Castle from viewpoint V6, location in Fig. 2 Photo: J. Ot'ahel' 

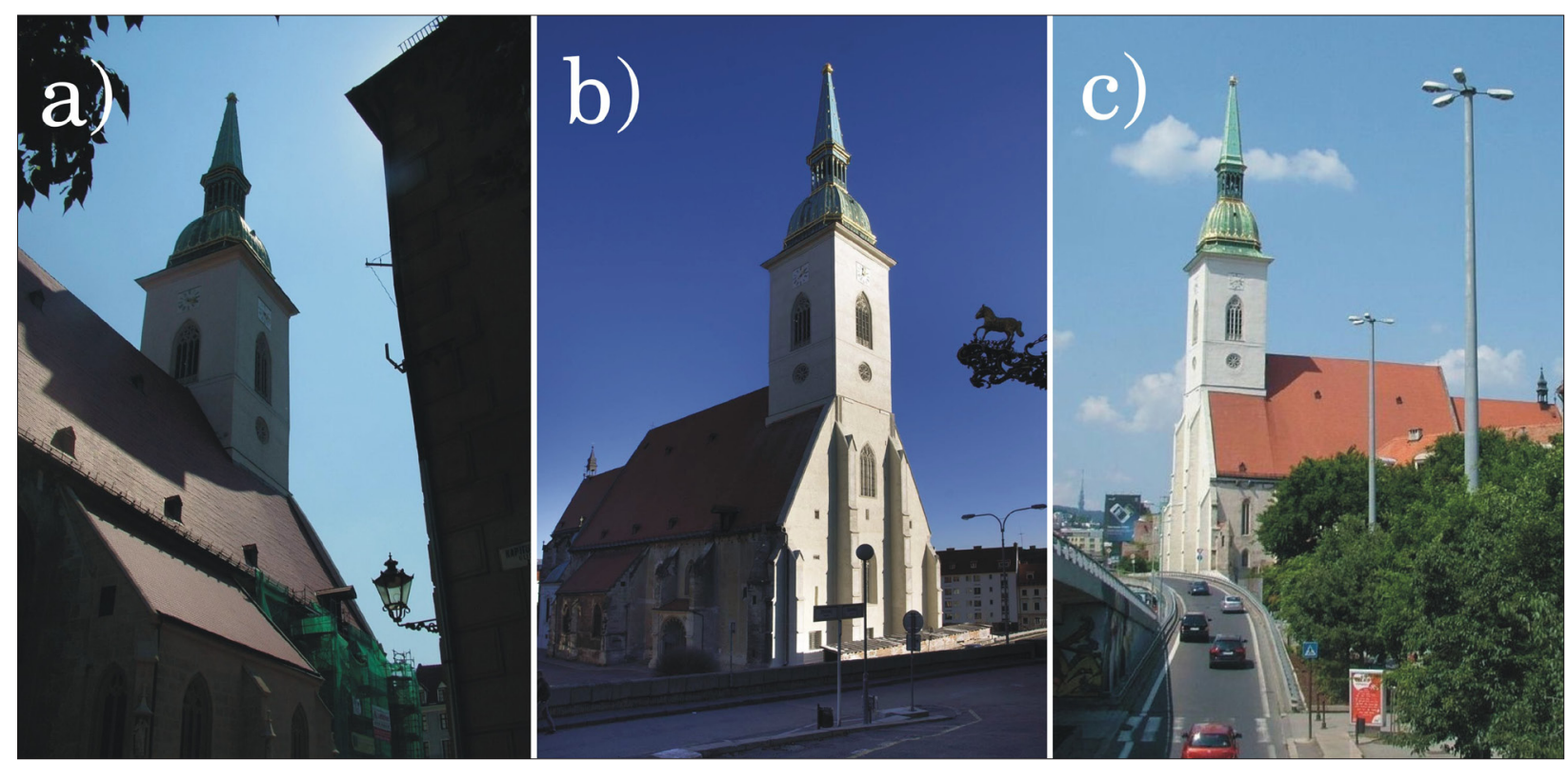

Fig. 8: Views of St. Martin's Cathedral (a) from viewpoint V4 (medium attractive), (b) from viewpoint V7 (very attractive), (c) from viewpoint V11 (very attractive) - location of viewpoints in Fig. 2. Photo: J. Ot'ahel'

attractive according to the visibility analysis (Tab. 3, Fig. 5a) because it facilitates the view of only two monuments $(\mathrm{L} 4, \mathrm{~L} 6)$, but it is the second best with respect to the positive replies of respondents $(90.9 \%$, Tab. 2). Likewise, viewpoints V2 and V5 are among the worst in visibility conditions, but the subjective approach ranks it among the best in terms of quality perception (over 80\%, Tab. 2). Viewpoint V6 (Tab. 3) ranks worst in the objective approach, but regarding the surrounding historic buildings (such as the Clarisse Church, Fig. 8b), it received a much higher score according to the subjective approach $(56.5 \%$, Tab. 2) with a medium attractive view of the Castle (Fig. 5b).

Comparisons of both approaches showed a similarity of the research results related to the viewpoints within a distance of less than $100 \mathrm{~m}$ from monuments (in the frame of comprehensive perception, see Fig. 4). The viewpoint and place of enquiry of viewpoint V4, for example, is located in the medium attractive visibility area regarding the distance, being very close to the Cathedral (Fig. 8a). This fact is reflected in the responses to survey questions asked at the place of enquiry (see Tab. 2, Fig. 5b). Accordance of the visibility assessment with the respondent's perception is evident for viewpoint V11 (Figs. 5b and 9c). The similarity in the assessment of the visibility and the respondents' perception was found in the example of viewpoint V7 (Tab. 4, Figs. 5a and $5 \mathrm{~b})$. The view over the busy traffic of Staromestská St. (Fig. 8b) has been mentioned as a disturbing effect on the viewpoint V7 (see Tab. 5, Fig. 10a).

The consistency of both assessments was found in perceptions of the Old Town Hall. According to visibility analysis, the visual perception from the legible (impressive) side of the monument was preferred. This preference was confirmed by responses to survey questions asked from the reverse side of Old Town Hall in viewpoint V2 (Fig. 9a, see Tab. 3). Different results were gained by evaluating the perception of the Old Town Hall from its impressive side on Hlavné Square (viewpoint V3, Tab. 3). Only one-half of the respondents judged the view as very attractive (Fig. 5b), because they perceived a large number of tourists as having a disturbing effect on this viewpoint (see Fig. 9b, Tab. 5).

The disturbing influence of street restaurants reduced the very attractive view of St. Michael's Gate from viewpoint V5 on Michalská St. (Fig. 5a, 10b, Tab. 4) to the level of medium attractive (Fig. 5b). Sigismund's Gate and Luginsland bastion were probably perceived as part of the Castle fortification because they were not quoted separately as impressive (representative) monuments (see Tab. 2).
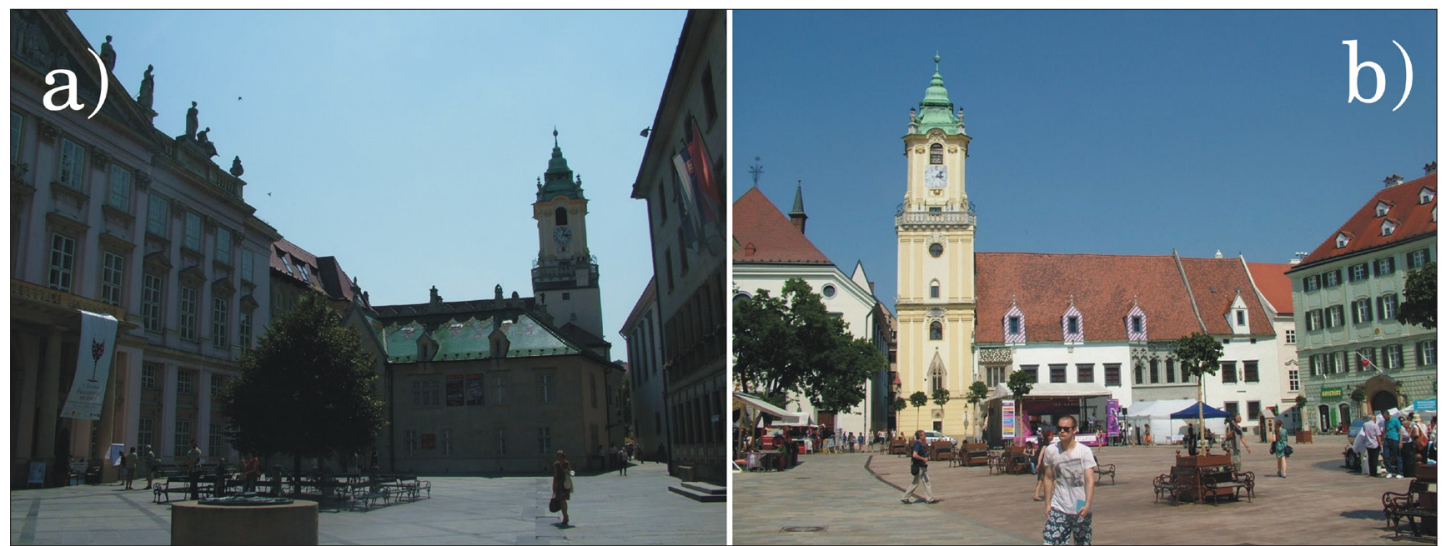

Fig. 9: Views of Old Town Hall (a) from viewpoint V2 (medium attractive), (b) from viewpoint V3 (Hlavné Sq., very attractive) - location of viewpoints in Fig. 2. Photo: J. Ot'ahel' 


\section{Conclusions}

The visibility conditions of eight monuments in the central area of Bratislava have been analysed in the first part of this paper. Using a data-driven approach, we computed practicable viewpoints for the observation of monuments to find very attractive viewpoints for each monument in its immediate vicinity (up to 100 m, see Fig. 4). The attractiveness of the viewpoints (visibility conditions and qualities) was measured by virtue of the monument's visibility criteria. The quality of visual perception identified using an objective approach was verified in 15 selected viewpoints, according to the results of the subjective respondent perception in the second part of this paper. According to the data, viewpoints that are rather remote from the historic Old Town and that provide views of several monuments (Fig. 11) and a comprehensive panoramic view of Bratislava's central area, were ranked best.

According to survey respondents, viewpoints in the historic Old Town (V3, V2, V5, see Tab. 4) or more remote viewpoints on the opposite bank of the River Danube

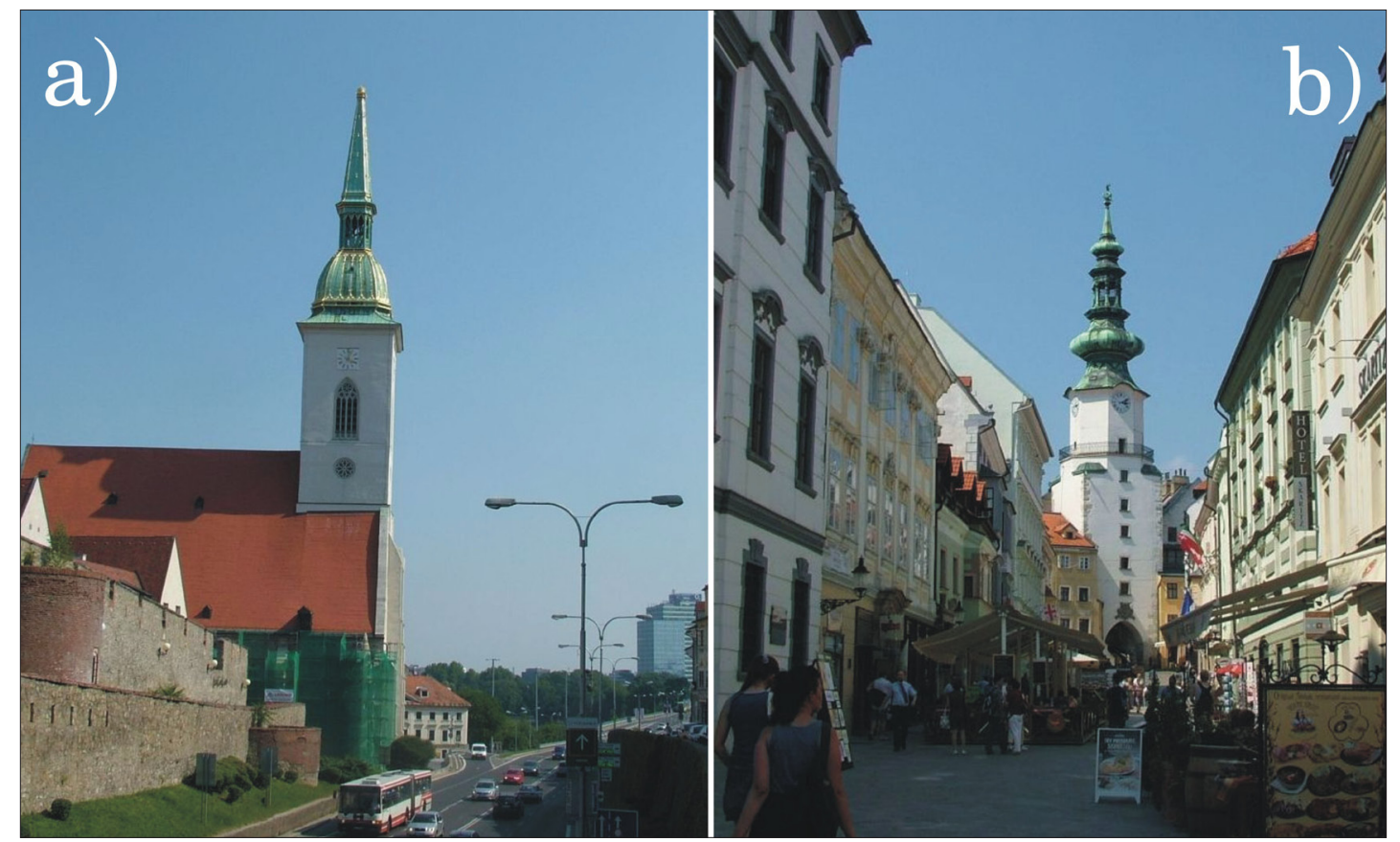

Fig. 10: Disturbing impact of views (a) from viewpoint V7, (b) from viewpoint V5 - location of viewpoints in Fig. 2 Photo: J. Ot'ahel'

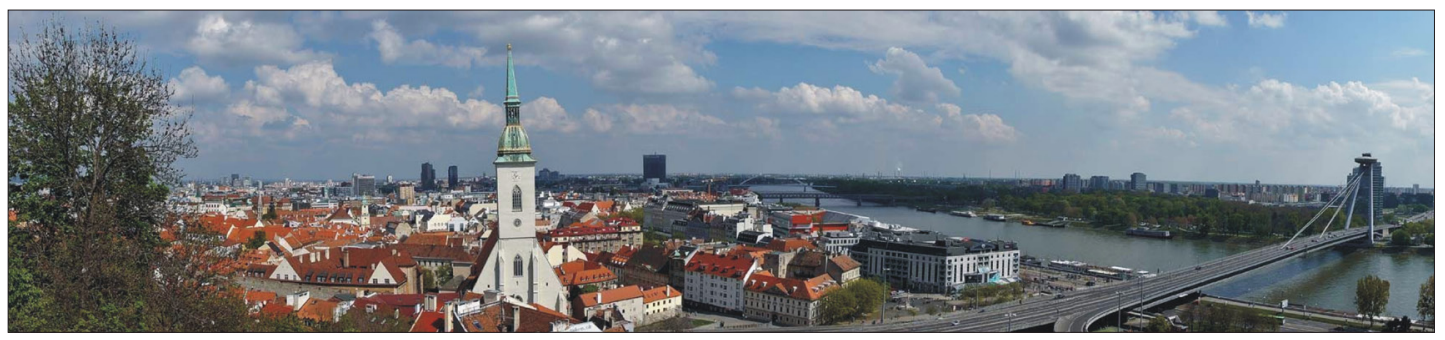

Fig. 11: View of the historical centre and of the Danube from Lower Castle terrace (V9). Photo: J. Lacika

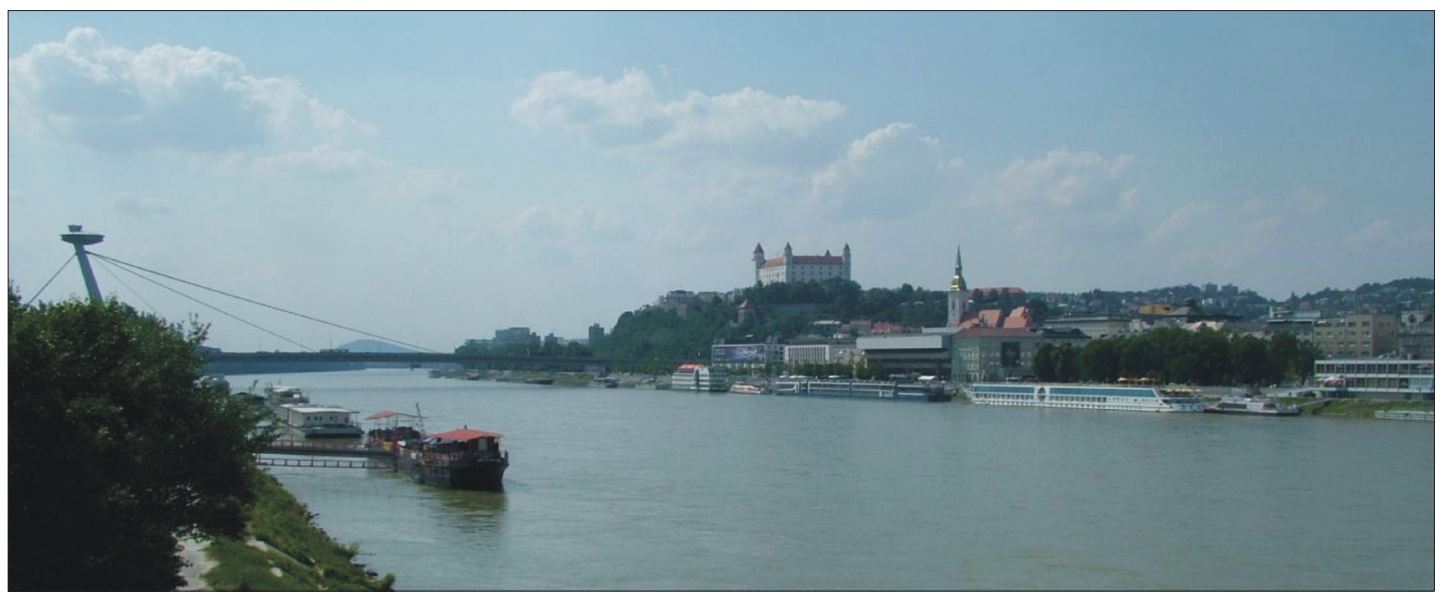

Fig. 12: View from the Old Bridge (V15). Photo: J. Ot'ahel' 
(V14, V15, see Tab. 4), which offer panoramic views of the city (Fig. 12), were marked positively and are among those with the highest quality perception of the city.

A comparison of the two approaches pointed to the valuable assets of visibility analysis for the assessment of viewpoints in terms of visibility conditions, attractiveness and the number of selected monuments. The independent (objective) visibility of monument analysis is considered as one of possible approaches to predict human perception and behaviour in urban environments (see Nijhuis et al., 2011; Van Lammeren, 2011; Fisher-Gewirtzman, 2016).

The assessment of viewpoints with the best visibility conditions makes it possible to propose effective viewing places and possible sightseeing routes. The assets of the subjective approach are appreciable for verifying very attractive viewpoints (with the best visibility conditions). Respondents' perceptions (human responses) are influenced by biological, cultural and individual factors (Jacobs, 2011). Using the described data-driven approach, therefore, could largely help to effectively design questionnaires that have high informative value for minimum costs. Respondents' perceptions, however, also pointed to the significance of the location of viewpoints for determining which environs were perceived as having either positive effects or negative disrupting effects. The viewpoints are classified by the best quality perceptions. This indicates that effects such as traffic, public movement intensity and soundscapes, need to be taken into account in further research. Generally, a subjective approach verifies to some extent and corrects also to some extent the results of an objective one, in this case.

Coupling an objective approach to the analysis of visibility conditions for city monuments with the verification of assessments concerning the attractiveness of viewpoints based on the perception of visitors and tourists using a subjective approach, has been presented here for the case of the central area of Bratislava, as a possible way to plan for the best locations for efficient sightseeing in cities.

\section{Acknowledgements}

This article has been written under the Projects No. 1/0052/17 "Suburban landscape: analysis of land cover changes and organization of socio-economic functions under the effect of urbanization and suburbanization processes" and No. 1/0082/15 "Specifics of time-space human behaviour under the impact of socio-economic changes", funded by the VEGA Grant Agency. We thank two anonymous reviewers and editor-in chief for helpful comments on a prior manuscript version.

\section{References:}

AMEDEO, D., GOLLEDGE, R., STIMSON, R. (2009): Person environment behaviour research: Investigating activities and experiences in spaces and environments. New York, London, Guilford Press.

APPLETON, J. (1975): The experience of landscape. Chichester, John Wiley and Sons.

ASHWORTH, G., PAGE, S. J. (2011): Urban tourism research: Recent progress and current paradoxes. Tourism Management, 32(1): 1-15.

BATTY, M. (2001): Exploring isovist fields: space and shape in architectural and urban morphology. Environment and Planning B: Planning and Design, 28(1): 123-150.
BAUDER, M., FREYTAG, T. (2015): Visitor mobility in the city and the effects of travel preparation. Tourism Geographies, 17(5): 682-700.

BELL, S. (1999): Landscape: pattern, perception and process. London, E\&FN Spon.

BENEDIKT, M. L. (1979): To take hold of space: isovists and isovist fields. Environment and Planning B: Planning and Design, 6(1): 47-65.

BERTAMINI, M., YANG, T. L., PROFFITT, D. R. (1998): Relative size perception at a distance is best at eye level. Perception \& Psychophysics, 60(4): 673-682.

BISHOP, I. D. (2003): Assessment of visual qualities, impacts, and behaviours, in the landscape, by using measures of visibility. Environment and Planning B: Planning and Design, 30(5): 677-688.

CAÑAS, I., AYUGA, E., AYUGA, F. (2009): A contribution to the assessment of scenic quality of landscapes based on preferences expressed by the public. Land Use Policy, 26(4): 1173-1181.

CHURCH, A., COLES, T. (2007): Tourism and many faces of power. In: Church, A., Coles, Z. [eds.]: Tourism, space and power (pp. 269-283). London, New York, Routledge.

DANIEL, T. C. (2001): Whither scenic beauty? Visual landscape quality assessment in the $21^{\text {st }}$ century. Landscape and Urban Planning, 54(4): 267-281.

DALTON, R. C., BAFNA, S. (2003): The syntactical image of the city: a reciprocal definition of spatial syntaxes. In International Space Syntax Symposium. London. Available at: http://www.spacesyntax/symposia/SSS4/ fullpapers/59DaltonBafnapapers.pdf

DE FLORIANI, L., MARZANO, P., PUPPO, E. (1994): Line-of-sight communication on terrain models. International Journal of Geographical Information Systems 8(4): 329-342.

DI LORENZO, G., READES, J., CALABRESE, F., RATTI, C. (2012): Predicting personal mobility with individual and group travel histories. Environment and Planning B: Planning and Design, 39(5): 838-857.

EDWARDS, D., GRIFFIN, T., HAYLLAR, B. (2008): Urban tourism research: developing an agenda. Annals of Tourism Research, 35(4): 1032-1052.

FISHER, P. F. (1995): An exploration of probable viewsheds in landscape planning. Environment and Planning B: Planning and Design, 22(5): 527-546.

FISHER-GEWIRTZMAN, D. (2016): Integrated 'weighted views' to quantitative $3 \mathrm{D}$ visibility analysis as a predictive tool for perception of space. Environment and Planning B: Urban Analytics and City Science https://doi.org/10.1177/0265813516676486

FYHRI, A., JACOBSEN, J. K. S., TŘMMERVIK, H. (2009): Tourists' landscape perceptions and preferences in a Scandinavian coastal region. Landscape and Urban Planning, 91(4): 202-211.

GARNERO, G., FABRIZIO, E. (2015): Visibility analysis in urban spaces: a raster-based approach and case studies. Environment and Planning B: Planning and Design 42(4): 688-707. 
GRANÖ, J. G. (1929): Reine Geographie: eine methodologische Studie beleuchtet mit Beispielen aus Finnland und Estland. Helsinki, Helsingfors.

GRASS DEVELOPMENT TEAM (2010): Geographic Resources Analysis Support System (GRASS) Software, Version 6.4.0, Open Source Geospatial Foundation. Available at: http://grass.osgeo.org

HLAVATÁ, Z., OŤAHEL, J. (2010): Visual analysis of selected historical dominants in Bratislava. Geografický časopis, 62(3): 239-311.

IRA, V. (2003): The changing intra-urban structure of the Bratislava city and its perception. Geografický časopis, 55(2): 91-107.

JACOBS, M. (2011): Psychology of the visual landscape. In: Nijhuis, S., et al. [eds.]: Exploring the visual landscape. (pp. 41-54). Delft, University of Technology.

JANEČKOVÁ MOLNÁROVÁ, K., SKŘIVANOVÁ, Z., KALIVODA, O., SKLENIČKA, P. (2017): Rural identity and landscape aesthetics in exurbia: Some issues to resolve from a Central Europe perspective. Moravian Geographical Reports, 28(1): 2-12.

KIDNER, D. B., RALLINGS，P. J.，WARE，A. J. (1997): Parallel processing for terrain analysis in GIS: visibility as a case study. GeoInformatica, 1(2): 183-207.

LIN, T., LIN, H., HU, M. (2017): Three-dimensional visibility analysis and visual quality computation for urban open spaces aided by Google SketchUp and WebGIS. Environment and Planning B: Urban Analytics and City Science 44(4): 618-646.

LLOBERA, M. (2003): Extending GIS-based visual analysis: the concept of visualscapes. International Journal of Geographic Information Science, 17(1): 25-48.

LOTHIAN, A. (1999): Landscape and the philosophy of aesthetics: is landscape quality inherent in the landscape or in the eye of the beholder? Landscape and Urban Planning 44(4): 177-198.

LYNCH, K. (1960): The Image of the City. Cambridge, MA, MIT Press.

MEILINGER, T., FRANZ, G., BÜLTHOFF, H. H. (2012): From isovists via mental representations to behaviour: first steps toward closing the causal chain. Environment and Planning B: Planning and Design 37(1): 48-62.

MORELLO, E., RATI, C. (2009): A digital image of the city: 3D isovists in Lynch's urban analysis. Environment and Planning B: Planning and Design, 36(5): 837-853.

NIJHUIS, S., VAN LAMMEREN, R., VAN DER HOEVEN, F. [eds.] (2011): Exploring the visual landscape. Delft, University of Technology.
NIJHUIS, S. (2011): Visual research in landscape architecture. In: Nijhuis, S. Van Lammeren, R., Van der Hoeven, F. [eds.]: Exploring the visual landscape (pp. 103-146). Delft, University of Technology.

NIJHUIS, S., VAN LAMMEREN, R., ANTROP, M. (2011): Exploring the visual landscape - Introduction. In: Nijhuis, S., Van Lammeren, R., Van der Hoeven, F. [eds.]: Exploring the visual landscape (pp. 15-39). Delft, University of Technology.

ODE, L., TVEIT, M. S., FRY, G. (2008): Capturing landscape visual character using indicators: touching base with aesthetic theory. Landscape Research, 33(1): 89-117.

OŤAHEL', J. (1999): Visual landscape perception. Landscape pattern and aesthetic assessment. Ekologia (Bratislava) 18(1): 63-74.

OŤAHEL', J. (2003): Visual quality of the landscape: approaches to analysis. Ekologia (Bratislava), 22(Suppl. 2): $150-160$.

ROOS-KLEIN LANKHORST, J, DE VRIES, S., BUIS, A. (2011): Mapping landscape attractiveness - A GIS-based landscape appreciation model for the Dutch countryside. In: Nijhuis, S., Van Lammer, R., Van der Hoeven, F. [eds.]: Exploring the visual landscape (pp. 147-161). Delft, University of Technology.

RØD, J. K., VAN DER MEER, D. (2009): Visibility and dominance analysis: assessing a high-rise building project in Trondheim. Environment and Planning B: Planning and Design, 36(4): 698-710.

SAARINEN, T. F. (1976): Environmental planning perception and behaviour. Boston, Houghton Mifflin.

SEVENANT, M., ANTROP, M. (2007): Settlement models, land use and visibility in rural landscapes: two case studies in Greece. Landscape and Urban Planning, 80(4): 362-374.

SPECTOR, R. H. (1990): Visual Fields. In: Walker, H. K., Hall, W. D., Hurst, J. W. [eds.]: Clinical Methods, $3^{\text {rd }}$ edition. The history, Physical and Laboratory examination (pp. 565-572). Atlanta, Georgia, Boston, Butterwortth Publishers, Emory University School of Medicine.

VAN LAMMEREN, R. (2011): Geomatics in physiognimc landscape research - A Dutch view. In: Nijhuis, S., Van Lammer, R., Van der Hoeven, F. [eds.]: Exploring the visual landscape (pp. 73-97). Delft, University of Technology.

ŻEMŁA, M. (2016): Tourism destination: The networking approach. Moravian Geographical Reports, 24(4): 2-14.

ZUBE, E. H., SELL, G. L., TAYLOR, J. G. (1982): Landscape perception: research, application and theory. Landscape Planning, 9: 1-33.

\section{Please cite this article as:}

OŤAHEL', J., IRA, V., HLAVATÁ, Z., PAZÚR, R. (2018): Visibility and perception analysis of city monuments: The case of Bratislava city centre (Slovakia). Moravian Geographical Reports, 26(1): 55-68. Doi: 10.2478/mgr-2018-0005. 